

\section{CREATIVE COMMONS}

\section{LICENSES}

\begin{tabular}{|c|c|}
\hline (2) & PUBLIC DOMAIN \\
\hline (1) & CC BY \\
\hline (1) (2) & CC BY-SA \\
\hline (1) $\ominus$ & CC BY-ND \\
\hline (1) 8 & CC BY-NC \\
\hline (1) $\$$ & CC BY-NC-SA \\
\hline (i) $\Leftrightarrow E$ & CC BY-NC-ND \\
\hline
\end{tabular}

\section{$\checkmark \quad \checkmark$}

You can redistribute You have to attribute

(copy, publish, disp

The Creative Commons licences explained.

for the original creation. This is the most accommodating of licences.

Are there too many licences? Should C BY be the default for text? The CC licences have become widely dopted both within and beyond ademia with over 48 million media They in provide a range Commons alone. give authors control over how their work can be reproduced and remixed.

The number and choice of licences as they stand work extremely well and offer an option to suit everyone's needs. It is certainly refreshing to see alternativa
to the norm in subscription-based publishing/publishers.

Should CC BY be the default for text? With reference to the text of academic materials, yes I think it should be.

DA and CC - are they separable? Can you expand on CC's relationship and thoughts on $O A$ ? Can a journal Yes, a journal can be open access
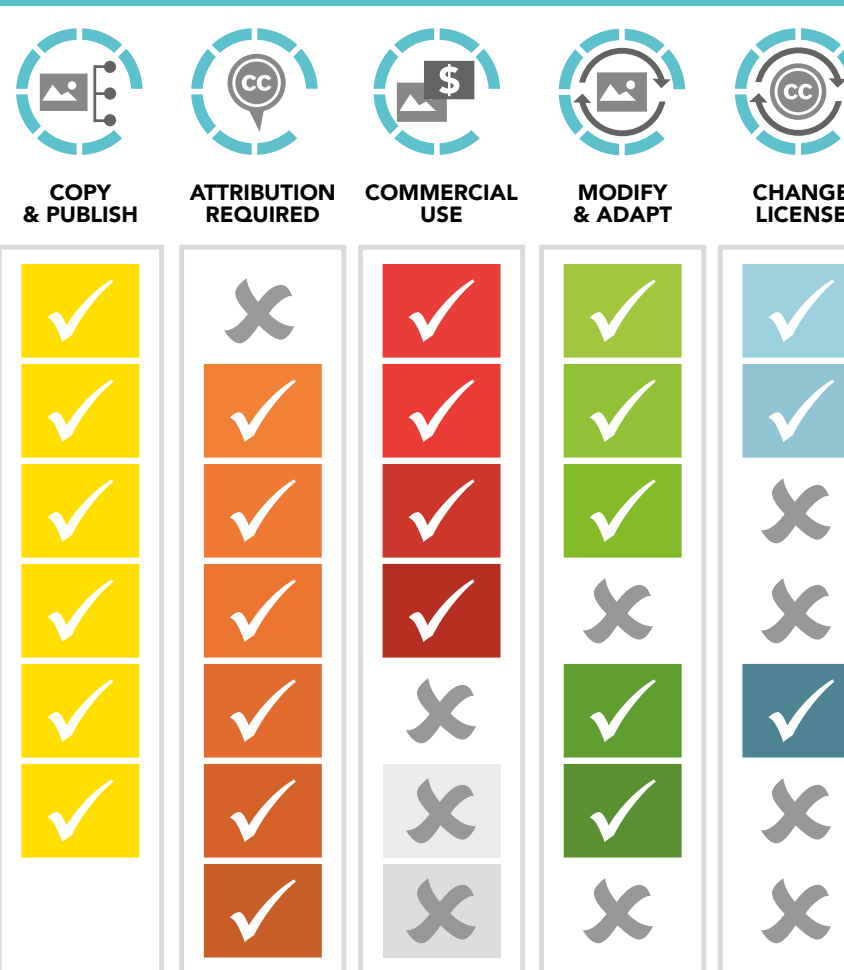
You can use the work
commercially

\section{$\checkmark$}

You can modify and
adapt the original work

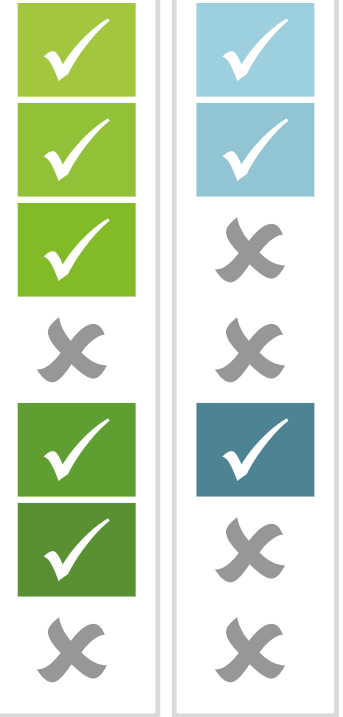

$\checkmark$

You can choose license type for your adaptations
of the work.
Elsevier's role in the European Union open science project.

$C C$ has been established for more tha 16 years now. What does the next five years hold? What are the strateg

CC has moved beyond simple licensing towards making the commons more vibrant and usable, and enabling more collaboration and gratitude to help it lourish. They are focused on a variety of initiatives and products to make this happen. An example of this is $\mathrm{CC}$ Search, currently in prototype, which is being built as a front door' to the commons. CC Search not only surfaces CC-licensed content that is freely available to anyone, it also provides with one click, and sentes up a massive collection of images by utilising open media application program interfaces.

Another example is the Creative Commons Certificate, an in-depth educational course about the ethos of openness, as well as CC licences and how they work. The course is without using a CC licence, but this is in the minority

CC has been and remains a pivotal element of OA. It has provided visiona thinking and evangelising about the conferences, and calling upon the $\mathrm{CC}$ bor directors to give talks about CC an CC hosted convenings, such as the 2006 Information Commons for Science Congress at the National Academies of Science in Washington, D.C., where renowned scientists and scholars from the United States and other countries gathered to discuss data-sharing strategies. In 2007, CC co-sponsored with the Committee on Data for Science and Technology (CODATA) the Workshop on Common Use Licensing of Scientific Data Products in Paris. This conference included representatives from the Global Biodiversity Information Facility, and leading legal scholars, policies. It was through this coll benefits and possibilities of $O A$ via scientists and CC International affiliates process that the Science Commons Data Protocol emerged as the best - and possibly only - solution to the challenges collectively identified at that time.

In the scientific and academic

digital technologies offer in terms efficient dissemination of $m$ morch and knowledge have not yet been fully harnessed - what are your thoughts

There has been substantial movement over the years in this regard, but agree there is certainly still much more that can and should be achieved. On the positive side, as of 2017, there are almost 1.5 billion CC-licensed works. There also has been a substantial

growth in the field of pre-prints and in a 2018 paper, Piwowar et al found that in 2015, 45\% of the scholarly literature is $\mathrm{AA}$. On the not so positive front, in 2011, George Monbiot released a sobering piece for The Guardian titled 'Academic publishers make Murdoch also rased very recently wh have ben communities, the benefits that available to everyone and is geared institutions to better advocate for openness and to help them be fully up to speed on how to interact with icences and CC-licensed works.

There's also the Creative Commons Summit, an annual event. The summit is an opportunity for everyone interested in this work to get together in person with an international community of technologists, to share ideas and decide on the best ways to move the movement forward.

Finally, there's the Creative Commons Global Network. This is a membership programe for organising, expanding f people who are actively invested

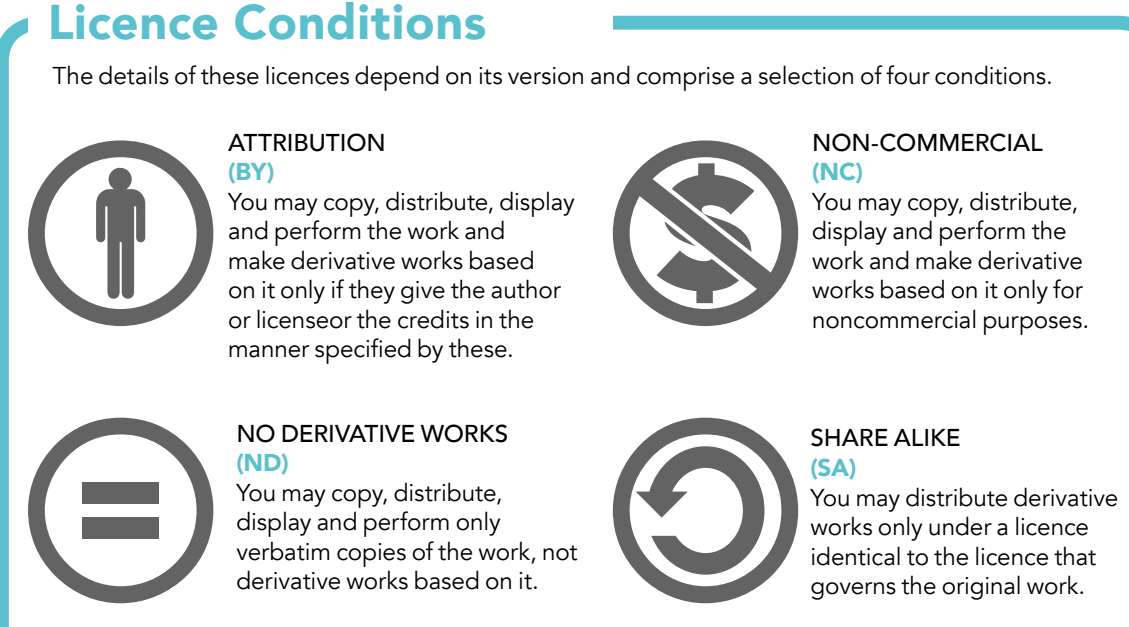

NOTE: A Iicence cannot feature both the Share Alike and No Derivative Works options

in making the world more open, and making culture more accessible and available to all.

Can you provide some links to hers can learn If you are in the United Kingdom and interested in CC, please feel free to join make Murdoch look like a socialist. The Guardian 29 August 2011. wnw. aug/29/academicommentisfree/2011/ socialist (date last accessed 26 October 2018).

Moody G. Elsevier will monitor open science in EU using a measurement

CC has moved beyond simple licensing, towards making the commons more vibrant and usable, and enabling more collaboration and gratitude.

the United Kingdom CC Slack channel (https://slack-signup.creativecommons. org/ and jump to CC UK).

vis the following links:

- Creative Commons

- Creative Commons FAO

- Choosing a CC licence

- How should I decide which licence to choose?

- Fact Sheet On Creative Common an Open Science

Creative Commons Licensing Explained

(video)

- Building on the Past' - An explanatio of how Creative Commons works. Winner of the Creative Commons Moving Image contest (video).

REFERENCES

Monbiot G. Academic publishers
Techdirt 09 July 2018 , www.techdirt 20180706/09314440182 esevier-will-monitor-open-science-eusing-measurement-system-that-favorsown-titles.shtml (date last accessed 26 er 2018).

Pirwowar $\mathrm{H}$, Priem J, Lariviere V, et al. The state of OA: a large-scale analysis Access articles. Peer J 6:e4375.

\section{Creative}

W: https://creativecommons.org/ 